\title{
LAS SEQUÍAS EN LA PAMPA HÚMEDA: IMPACTO EN LA PRODUCTIVIDAD DEL MAÍZ
}

\author{
J. L. MINETTI ${ }^{1}$, W. M. VARGAS ${ }^{2}$, B. VEGA ${ }^{3}$ y M. C. $\operatorname{COSTA}^{4}$ \\ ${ }^{1}$ Universidad Nacional de Tucumán (UNT), CONICET - Dpto. de Geografía, \\ Laboratorio Climatológico Sudamericano (LCS).E-mail: minettil@arnet.com.ar \\ ${ }^{2}$ Universidad de Buenos Aires y Laboratorio Climatológico Sudamericano (LCS), \\ CONICET - Dpto. Cs. de la Atmósfera y el Mar. \\ ${ }^{3}$ Universidad Nacional de Tucumán (UNT), Dpto. de Geografía. \\ ${ }^{4}$ Universidad Nacional de Tucumán (UNT) - Laboratorio Climatológico Sudamericano (LCS), \\ Fac. de Agronomía y Zootecnia.
}

Recibido Octubre 2005 - Aceptado Agosto 2006

\begin{abstract}
RESÚMEN
Se identifican las sequías climáticas ocurridas en el espacio y tiempo durante el siglo pasado para la Pampa Húmeda. Haciendo uso de índices de sequía mensual, trimestral y anual propuestos se analizan algunas de las propiedades estadísticas como la persistencia, marcha temporal y distribución espacial, entre otras. También se muestran las potenciales consecuencias de las sequías sobre la productividad de un cultivo de importancia regional como el maíz, muy sensible a la misma. Para ello se elabora y evalúa un modelo de diagnóstico entre este estado del clima y la productividad del maíz para analizar los impactos.
\end{abstract}

Palabras claves: sequía, Pampa Húmeda, maíz.

\begin{abstract}
DROUGHTS IN THE PAMPA HUMEDA-IMPACT IN THE PRODUCTIVITY OF CORN.

This work seeks to identify droughts events in the space-time that occurred during the last century in Humid Pampas (Argentina). By means of the drought-index, statistical properties such as persistence, extremes and trends are analyzed. Since corn is drought sensitive, this study also attempts to show potential consequences of drought on the productivity of this important region crop. For that, an interaction model between droughts and productivity-impacts is elaborated and evaluated.
\end{abstract}

Keywords: drought, Pampa Húmeda, corn.

\section{INTRODUCCION}

Desde el punto de vista geográfico interesan las sequías por sus impactos, y las áreas de influencia pueden elegirse de acuerdo a criterios físicos (climáticos) y/ o económicos. Desde un punto de vista agronómico se observa sequía cuando el nivel de almacenaje del agua en el suelo ha bajado lo suficiente como para afectar el desarrollo o mantenimiento de una planta. En algunos casos, esta falta de agua es tan importante en períodos críticos de un cultivo (Doorenbos y Pruitt, 1976), que genera una disminución de los rindes en el momento de la cosecha o baja de productividad.
Las sequías han sido objeto de gran preocupación en las principales praderas del mundo, por su influencia en la producción de alimentos, y también en la degradación de recursos edáficos (erosión eólica). Es importante recordar que en la década del 30 (1934-36 y 39) en Estados Unidos la combinación de devastadoras sequías asociadas a una intensa presión antrópica sobre los márgenes más secos de la pradera generados en parte por la agricultura, originaron grandes daños en el suelo, y han dado lugar a las leyes actuales de uso y conservación del suelo de ese país (Stockton y Meko, 1983). Los autores citados además han encontrado una importante recurrencia de aparición de períodos secos del orden de 
22 años. Estas observaciones han sido estimadas con el crecimiento de anillos de los árboles de series procedentes de la Dendrocronología y han coincidido con las investigaciones de Marshall (1972) y Roberts (1975) entre otros, que realizaron estudios con datos de lluvias en las altas planicies de América del Norte. En la Argentina semiárida subtropical y tropical, Vargas y otros (2002) encontraron oscilaciones del período mencionado en el régimen de la variabilidad interanual de las lluvias.

Desde el punto de vista agronómico y económico, es de gran interés para la actividad humana en la llanura Este de Argentina denominada Pampa Húmeda, el análisis del impacto que las sequías han tenido en un cultivo de gran difusión regional como el maíz. Este cultivo tiene gran sensibilidad a los cambios de las lluvias con el tiempo, debido a su escasa extensión radicular (extractora de agua) en la capa sub-superficial del suelo y una gran superficie foliar consumidora de agua (Sierra y Pórfido, 1980). Esto lo hace apto para estudiar su rendimiento en función solo del clima y por otra parte permite acotar el interés de este estudio a las llamadas sequías climáticas.

El impacto de las sequías se manifestó en el pasado en la superficie sembrada del cereal, en los rindes por unidad de superficie (productividad), en los recursos económicos de los productores que ingresaron al país, menos capital por las exportaciones y como consecuencia al menor desarrollo de la Pampa Húmeda y del país. En forma similar a lo ocurrido en USA sobre mediados del siglo pasado, la gran sequía de 193040 en Argentina hizo que el gobierno nacional, pensara en un plan alternativo de erradicar a los colonos del Oeste de Buenos Aires y provincia de La Pampa afectados por grandes dunas invasoras (Kugler, 1983) derivadas de las sequías, y tuvo que ver con problemas de migraciones internas.

Que la mayor parte de Argentina haya soportado en las últimas décadas un cambio en el régimen hídrico de gran escala presentándose más lluvioso a partir de la década de 1950-60 (Hoffmann, 1988, Minetti y Vargas, 1998), hace que el estudio temporal de las sequías sea importante. La selección de la Pampa Húmeda como región de estudio obedece por lo tanto a razones de orden económico por la importancia de los impactos de las sequías en la productividad de los cultivos que se realizan en secano (sin riego). En otras regiones de la Argentina se observan también eventos secos que tienen duración, intensidad, y áreas de cobertura que dependen de las distintas características climáticas regionales. La región analizada se ubica dentro de los climas húmedos de bosque o pradera Cf de Koeppen (1931) con una distribución isohigro de precipitaciones mensuales, aunque se reconocen dos máximos de lluvias estacionales, una en primavera y otra en otoño y un mínimo de invierno. La variabilidad interanual de las precipitaciones en la región está discriminada en tres regiones de Norte a Sur por diversos modelos que tienen en común una tendencia creciente de las precipitaciones con los años (Minetti y otros, 2004). Las precipitaciones en la región reconocen una génesis dominante que es la de tipo frontal en un $91 \%$ de casos (Wolcken, 1954). Otro aspecto general de la región Subtropical Argentina muestra que la ausencia de precipitaciones en un lapso de 10 a 12 días, puede considerarse una sequía meteorológica si consideramos que el intervalo más frecuente entre dos lluvias es del orden de 5-6 días (Minetti y Sierra, 1983).

Para la definición general y objetiva de los eventos de sequías se tienen que adoptar diferentes criterios según la finalidad del estudio a realizar, y los datos disponibles. Una gran cantidad de índices de sequías han sido usados para definir o evaluar al fenómeno (Heim, R. and Dracup, 2002, Keyanthash, J. and Dracup, J., 2002), pero todos ellos requieren diversos grados de información para computarlos. Sin embargo cuando la sequía es definida como climática y el impacto es sobre un cultivo muy sensible a la lluvia como el maíz, el índice puede ser estimado en función de esa información climática.

En general en las escalas regionales como la de este estudio, es difícil encontrar bases de datos que permitan inferir con mucha precisión todos los aspectos de una sequía, salvo lo que muestran los datos climáticos, en especial la precipitación. Por esto se intenta aquí estudiar a las sequías meteorológicas o climáticas y sus impactos regionales en un cultivo altamente sensible a ellas, sin entrar en los detalles que permitirían reconocer algunas causas de escala local (almacenaje de agua en el suelo, profundidad de napas freáticas, entre otras) ni tampoco los orígenes de esta en la gran escala. También se percibe apoyado en el conocimiento general que las anomalías negativas de lluvias (sequías climáticas) son eventos de tipo extensivo (que abarcan grandes superficies geográficas) a diferencia de los episodios lluviosos que pueden estar restringidos a escalas geográficas más pequeñas (mesoescala).

Para identificar a las sequías regionales Minetti y otros (2001a) han generado un índice de sequía areal que usaron en seis regiones en el Cono Sur de América. Este inventario usa las localidades afectadas por este evento seco y las relaciona con el total de localidades utilizadas en cada región. En ese trabajo también se puede ver que la intensidad de una sequía es función lineal de su cobertura espacial, de tal manera que las sequías de mayor área son más intensas, o de mayor apartamento negativo de la normalidad. También ha sido el índice más sencillo de calcular con los datos disponibles y de su cómputo se han identificado sequías mensuales, estacionales, rachas, años secos, etc. La ubicación temporal de las sequías y su dispersión espacial, se determinan a los efectos de emplearlos en estudios posteriores sobre los impactos.

En una escala mensual se puede definir como sequía climática sin importar la intensidad de estas, cuando la precipitación total de un mes es menor que su valor central (mediana), en un conjunto de localidades que igualan o superen 
el 70\% de las evaluadas en una región. La ocurrencia de rachas negativas (Yevjevich, 1972b, Vargas, 1979) pueden constituir sequías estacionales o anuales.

Tomando en cuenta lo expuesto anteriormente se proponen los siguientes objetivos:

El primero sería la identificación de los meses con sequías, rachas secas, períodos estacionales y años secos en la Pampa Húmeda, mediante el uso de un índice de sequía propuesto.

El segundo pretende obtener algunas propiedades estadísticas de las series temporales del índice de sequía para ser comparado con los de las otras regiones vecinas, y analizar el impacto de los cambios de larga escala del clima sobre la variabilidad interanual.

El tercer objetivo es intentar usar y validar al índice de sequía propuesto como elemento de diagnóstico del impacto de las condiciones hídricas observadas sobre la productividad de un cereal (maíz) de gran sensibilidad a la sequía. En este caso particular se intenta aclarar cómo se deberían analizar los efectos de los cambios de baja frecuencia del clima y los de la tecnología que se mezclan por razones de escala.

\section{DATOS Y METODOS}

Se han empleado datos pluviométricos mensuales de localidades ubicadas en la Pampa Húmeda Argentina -PHque incluyen al Sur de la provincia de Santa Fé, provincia de Entre Ríos y la provincia de Buenos Aires en el período 1903-2001. Estas localidades se identifican en la figura $1 \mathrm{a}$. La figura $1 \mathrm{~b}$ muestra a las otras regiones analizadas con idéntica metodología a los efectos comparativos pero no se muestra su red pluviométrica. Ellas son: Noroeste Argentino (NOA), Noreste Argentino (NEA), Centro-Oeste Argentino (COA), Patagonia (PAT) y Centro de Chile-Comahue (CHI). La información ha sido controlada (consistida) para la detección de errores aleatorios y sistemáticos según lo propuesto por WMO (1966). Los datos provienen del Servicio Meteorológico Nacional y la base controlada la proporcionó el Laboratorio Climatológico Sudamericano de la Fundación Caldenius. Para la detección de sequías areales que afectaran a la región se utilizó el método propuesto por Minetti (1999), que utiliza los totales mensuales de precipitación en las estaciones de la región. El mismo consiste en lo siguiente: 1 . Se obtiene la matriz de anomalías mensuales de precipitaciones estimadas como la diferencia entre el valor observado menos su mediana mensual. Esto en cada localidad (pluviómetro) considerada. 2. Si bien es cierto que una débil anomalía negativa de precipitación puntual, no representa necesariamente una sequía, la intención es detectar la cobertura areal de las anomalías negativas. Para ello se estima la proporción de localidades (pluviómetros) con anomalías negativas respecto al total de localidades (pluviómetros) utilizados en la región. Esta proporción se la llama Índice Mensual de Sequía (IMS). Este índice da una idea del área afectada. Se advierte que $0 \leq \mathrm{IMS} \leq 1$ a)

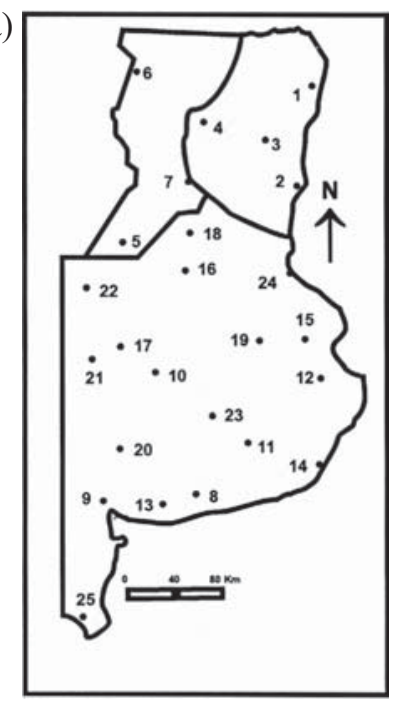

b)

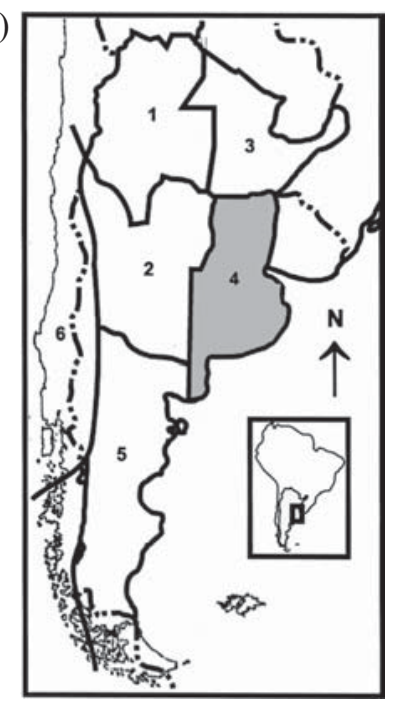

Figura 1 - (a) Región de estudio y ubicación de las localidades con información pluviométrica. 1-Concordia, 2-Gualeguaychú, 3-Villaguay, 4-Paraná, 5-Clason, 6-Rafaela, 7-Rosario, 8-Tres Arroyos, 9-B.Blanca, 10-Bolívar, 11-Tandil, 12-Dolores, 13-Cnl.Dorrego, 14-M.del Plata, 15-Chascomús, 16-Junín, 17-Pehuajó, 18-Pergamino, 19-Saladillo, 20-Cnl.Suárez, 21-T.Lauquen, 22-Grl.Villegas, 23-Azul, 24-B.Aires, 25-C.de Patagones. (b) Subregiones con evaluación del índice de sequía en el Cono Sur de América.

Se define luego el Índice Anual de Sequía (IAS) como la suma de los doce IMS correspondiente a cada mes del año. Notar que: $0 \leq \mathrm{IAS} \leq 12$

Se define una sequía mensual de gran cobertura areal aquella que tiene un IMS $\geq 0.7$ o sea un $70 \%$ o más de localidades con anomalías negativas. Estos meses han sido representados con una $(\mathrm{X})$ en la tabla 1 .

Si todos los meses poseen este nivel de cobertura (0.7) el índice anual IAS $\geq 8.4$, valor que hace referencia el texto como nivel crítico. Estos valores anuales han sido graficados con una (X) en la tabla 2 donde se muestra comparativamente a la Pampa Húmeda con las otras regiones del Cono Sur de América.

El Índice Mensual de Intensidad de las Sequías fue evaluado mediante el cómputo del IMIS que puede ser estimado como sigue:

- Se obtiene la matriz de los ordenes NI obtenidos con los deciles mensuales correspondiente a cada total mensual de precipitación. Esto en cada localidad (pluviómetro) considerada.

- Para obtener el índice se usa el criterio que se indica a continuación en la tabla 3. El promedio de los NI de todas las localidades constituye un índice de área-intensidad de una sequía. 
Tabla 1 - Períodos secos mensuales (con IMS $\geq 0$ 0.7) en la Pampa Húmeda. Período 1903-04 a 2000-01. MS indica la cantidad de meses secos al año.

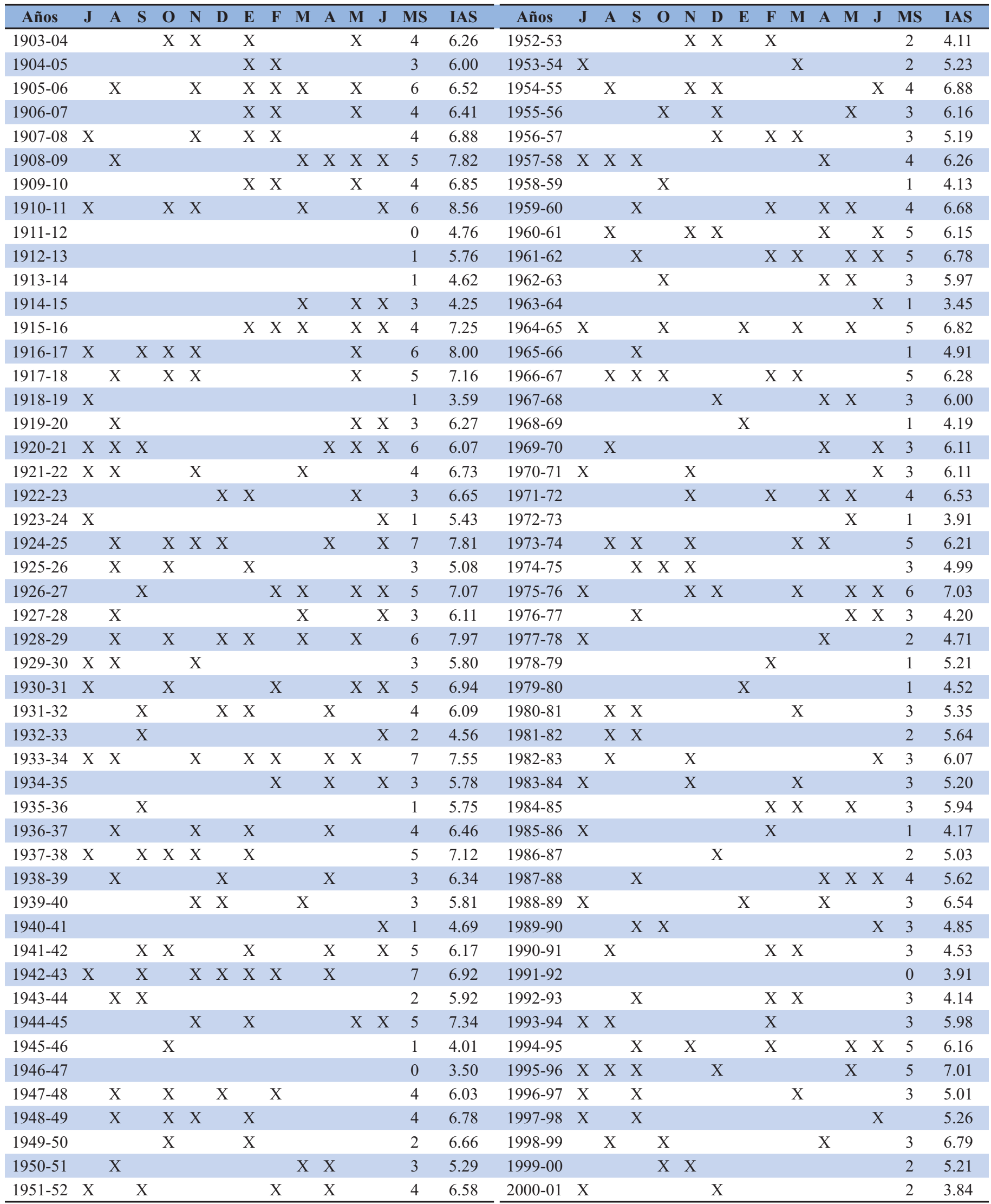


Tabla 2 - Eventos secos anuales para regiones del Cono Sur de América (con IAS $\geq 8.4$ ).

\begin{tabular}{|c|c|c|c|c|c|c|c|c|c|c|c|c|c|c|c|}
\hline Años & NOA & $\mathrm{CO}$ & NEA & $\mathbf{P H}$ & PAT & CHI & TOT & Años & NOA & $\mathrm{CO}$ & NEA & $\mathbf{P H}$ & PAT & $\mathrm{CHI}$ & TOT \\
\hline 1903-04 & & & $\mathrm{X}$ & & & & 1 & $1952-53$ & & & & & & $X$ & 1 \\
\hline 1904-05 & & & & & & & 0 & $1953-54$ & & & & & & & 0 \\
\hline $1905-06$ & & $\mathrm{X}$ & & & & & 1 & $1954-55$ & & & & & & & 0 \\
\hline $1906-07$ & $X$ & & $X$ & & & $X$ & 3 & $1955-56$ & $X$ & & $X$ & & & & 2 \\
\hline $1907-08$ & & & & & $\mathrm{X}$ & & 1 & $1956-57$ & & & & & & $X$ & 1 \\
\hline 1908-09 & & $\mathrm{X}$ & & $X$ & $X$ & $\mathrm{X}$ & 4 & $1957-58$ & & & & & & & 0 \\
\hline $1909-10$ & & $\mathrm{X}$ & & & & & 1 & $1958-59$ & & & & & & & 0 \\
\hline 1910-11 & $\mathrm{X}$ & $\mathrm{X}$ & $X$ & $X$ & & & 4 & $1959-60$ & & & & & & & 0 \\
\hline $1911-12$ & & & & & & & 0 & $1960-61$ & & & & & $X$ & & 1 \\
\hline $1912-13$ & & & & & & & 0 & $1961-62$ & X & & & & & X & 2 \\
\hline 1913-14 & & & & & & & 1 & $1962-63$ & & & & & $X$ & X & 2 \\
\hline $1914-15$ & X & & & & & & 1 & 1963-64 & & & X & & & & 1 \\
\hline 1915-16 & X & X & X & X & X & & 5 & 1964-65 & X & & & & & & 1 \\
\hline $1916-17$ & X & X & X & $X$ & & & 4 & $1965-66$ & & & & & & & 0 \\
\hline 1917-18 & & & & $\mathrm{X}$ & $\mathrm{X}$ & & 2 & $1966-67$ & $\mathrm{X}$ & $\mathrm{X}$ & & & & & 2 \\
\hline 1918-19 & $X$ & & & & & & 1 & $1967-68$ & & & & & $X$ & $X$ & 2 \\
\hline $1919-20$ & & & & & & & 0 & 1968-69 & & & & & & & 0 \\
\hline $1920-21$ & & & & & $X$ & & 1 & $1969-70$ & & $\mathrm{X}$ & & & & & 1 \\
\hline $1921-22$ & & & & & & $\mathrm{X}$ & 1 & $1970-71$ & & $\mathrm{X}$ & & & & & 1 \\
\hline $1922-23$ & & & & & & & 0 & $1971-72$ & X & & & & & & 1 \\
\hline $1923-24$ & $\mathrm{X}$ & & & & & & 1 & $1972-73$ & & & & & & & 0 \\
\hline $1924-25$ & & $X$ & $\mathrm{X}$ & $X$ & $X$ & X & 5 & $1973-74$ & & & & & & & 0 \\
\hline $1925-26$ & & & & & & & 0 & $1974-75$ & & & & & & & 0 \\
\hline $1926-27$ & & & & & & & 0 & $1975-76$ & & & $\mathrm{X}$ & & & & 1 \\
\hline $1927-28$ & & & & & $X$ & & 1 & $1976-77$ & & & & & & & 0 \\
\hline $1928-29$ & & & & $X$ & & & 1 & $1977-78$ & & & & & & & 0 \\
\hline $1929-30$ & & $\mathrm{X}$ & & & & & 1 & $1978-79$ & & & & & & $\mathrm{X}$ & 1 \\
\hline $1930-31$ & & & & & & & 0 & $1979-80$ & & & & & & & 0 \\
\hline $1931-32$ & & & & & & & 0 & 1980-81 & & & & & & & 0 \\
\hline $1932-33$ & & & & & & & 0 & $1981-82$ & & & & & & X & 1 \\
\hline $1933-34$ & $\mathrm{X}$ & $X$ & $X$ & $X$ & & & 4 & $1982-83$ & & & & & & & 0 \\
\hline $1934-35$ & & & $X$ & & & & 1 & $1983-84$ & & & & & & $\mathrm{X}$ & 1 \\
\hline $1935-36$ & X & & & & & & 1 & $1984-85$ & & & & & & & 0 \\
\hline $1936-37$ & $X$ & $X$ & $X$ & & & & 3 & $1985-86$ & & & & & & & 0 \\
\hline $1937-38$ & $\mathrm{X}$ & $X$ & & & & & 2 & $1986-87$ & & & & & & $\mathrm{X}$ & 1 \\
\hline 1938-39 & $X$ & X & $X$ & & & & 3 & $1987-88$ & & & & & & $X$ & 1 \\
\hline $1939-40$ & & & & & & & 0 & 1988-89 & X & & X & & $X$ & $X$ & 4 \\
\hline $1940-41$ & & & & & & & 0 & $1989-90$ & & & & & & $X$ & 1 \\
\hline $1941-42$ & & & & & & & 0 & 1990-91 & & & & & & $X$ & 1 \\
\hline $1942-43$ & & & $X$ & & & & 1 & 1991-92 & & & & & & & 0 \\
\hline $1943-44$ & & & $X$ & & & & 1 & $1992-93$ & & & & & & & 0 \\
\hline $1944-45$ & & $X$ & $X$ & $X$ & & & 3 & 1993-94 & & & & & & & 0 \\
\hline $1945-46$ & & & & & & & 0 & 1994-95 & & & & & & & 0 \\
\hline $1946-47$ & & & & & & & 0 & $1995-96$ & & & $X$ & & & $X$ & 2 \\
\hline $1947-48$ & & & & & $X$ & & 1 & $1996-97$ & & & & & & $X$ & 1 \\
\hline $1948-49$ & X & X & & & & & 2 & 1997-98 & & & & & & & 0 \\
\hline $1949-50$ & & & & & & & 0 & 1998-99 & & & & & & X & 1 \\
\hline $1950-51$ & X & & & & & & 1 & 1999-00 & & & & & & X & 1 \\
\hline $1951-52$ & & $\mathrm{X}$ & & & & & 1 & 2000-01 & & & & & & & 0 \\
\hline
\end{tabular}


Tabla 3 - Criterios interdecílicos de clasificación de una precipitación mensual.

\begin{tabular}{|c|c|c|c|c|c|c|c|c|c|c|}
\hline $\begin{array}{c}\mathrm{NI} \\
\text { (índice) }\end{array}$ & 0 & 1 & & 2 & 3 & & 4 & 5 & & 6 \\
\hline Decíl & $\mathrm{mA} \quad \mathrm{D} 1$ & & D2 & D4 & & D6 & D8 & & D9 & MA \\
\hline Evento & & Sequia & & & Normal & & & Lluvioss & & \\
\hline
\end{tabular}

$\mathrm{mA}=$ mínimo absoluto; $\mathrm{MA}=$ Máximo Absoluto; $\mathrm{Di}=$ decil

$$
\mathrm{IMIS}=\frac{\left(\sum_{1}^{\mathrm{N}} \mathrm{NI}\right)}{\mathrm{N}}
$$

Donde:

IMIS = Índice mensual de intensidad de sequía de una región $\mathrm{NI}=$ Índice mensual de intensidad de sequía de una localidad geográfica

$\mathrm{N}^{\mathrm{o}}=$ Número de localidades

Se advierte aquí que $0 \leq$ IMIS $\leq 6$

El Índice Anual de Intensidad de Sequías IAIS es la suma de los doce valores de IMIS. Se advierte aquí que $0 \leq$ IAIS $\leq 72$

Finalmente a partir de la matriz de anomalías negativas de cada localidad computada en períodos que van de 88-141 años se han calculado los índices de sequías propuestos los períodos agrícolas (julio-junio)1909-10/1996-97. En los análisis regionales se ocupó el período 1903-04 al 2000-01.

Posteriormente se muestra que hay una relación lineal directa entre el área de cobertura de una sequía (IMS mensual) o (IAS anual) con su intensidad-área (IMIS mensual) o (IAIS anual). Esto se podrá ver en el ejemplo de la figura 2.

La relación lineal existente entre ambos índices hizo que se optara para el análisis el empleo de los índices areales y no los de área-intensidad. Posteriormente estos índices han sido analizados con métodos estadísticos independientes y dependientes del tiempo (series temporales) (Yevjevich, V., $1972 \mathrm{a}, \mathrm{b})$.

Los datos de rendimientos agrícolas anuales del maíz fueron obtenidos de los Anales de la Bolsa de Cereales de Buenos Aires. Esta información anual es promedio del país pero como la mayor difusión del cultivo se ubica en la Pampa Húmeda (Centro Editor América Latina, 1984), se han tomado éstos como representativos de la región de mayor difusión (la Pampa Húmeda). La figura 3 muestra la densidad del cultivo en esta región observándose la mayor concentración sobre los partidos de Pergamino (Provincia de Buenos Aires) y BelgranoIriondo (Provincia de Santa Fé).

Para el estudio de impactos se han explorado las asociaciones entre los índices de sequías mensuales (IMS)

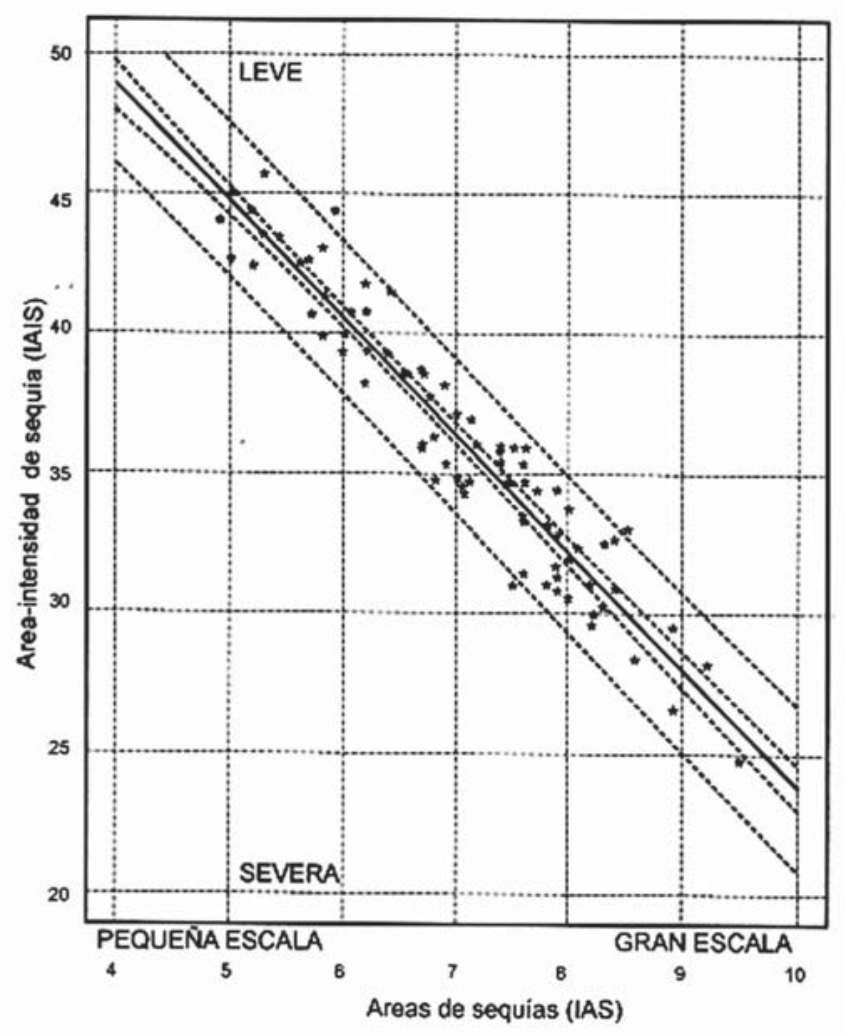

Figura 2 - Relación lineal entre los índices de sequías IAS (areal) e IAIS (área-intensidad).

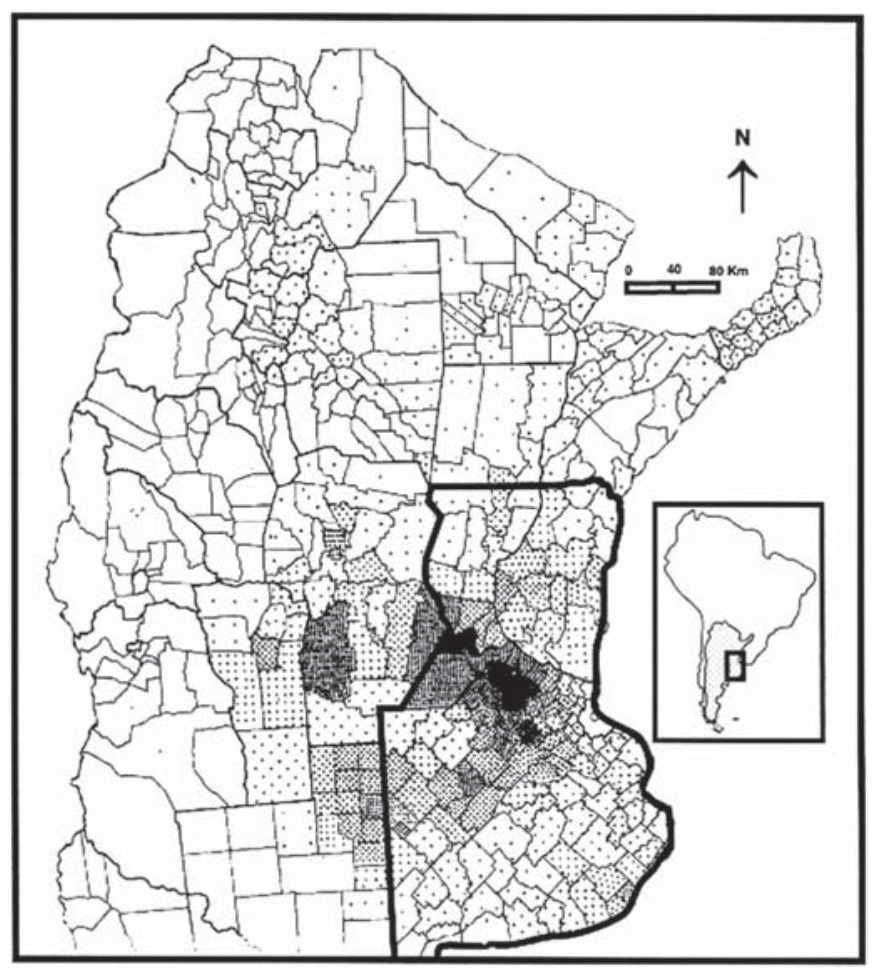

Figura 3 - Densidad del cultivo del maíz. Cada punto indica 1000 ha. 
con los rendimientos medios anuales del maíz. De la matriz de correlación generada entre predictores hídricos (IMS) y rendimientos anuales (Johnston, 1972) se han seleccionado los períodos de mayor impacto del IMS y recalculadas las correlaciones para períodos mayores donde se producen los principales impactos entre el clima y el cultivo. Estas relaciones bi-variadas han sido modeladas como funciones lineales o curvilíneas. Para estos cómputos se han usado dos metodologías, I) filtrando previamente las tendencias de variables climáticas y rendimientos (Sierra y Brynsztein, 1989). y II) sin filtro a los efectos de agregar los impactos de cambios de larga escala observados en ambas variables.

\section{RESULTADOS Y DISCUSIÓN}

\subsection{Sequías anuales (años secos):}

La tabla 2 presenta para comparación los eventos secos importantes (los que tienen índice anual IAS $\geq 8.4$ ) para las regiones seleccionadas en el Cono Sur de América durante el período 1903-04 y 2000-01.

De esta tabla surge que los eventos secos generalizados o con mayor cantidad de regiones geográficas involucradas (5 regiones) en Argentina-Chile, han ocurrido en los años 1915-16 y 1924-25, los de segundo orden de importancia (4 regiones) le siguen los de 1908-09, 1910-11, 1916-17, 1933-34 y 1988-89, y los de tercer orden (3 regiones) en 1906-07, 1936-37, 1938-39 y 1944-45. También se muestra aquí que la década de mayor ocurrencia de eventos en gran escala fue la de 1931-40, siguiéndoles las de 1911-20 y 1901-10, aunque en esta última existen dos años sin datos analizados.

En los eventos generalizados de primer y segundo orden de importancia (5 a 4 regiones), la Pampa Húmeda se encuentra afectada por el fenómeno, no así en los de tercer orden (salvo en el año 1944-45). Desde este año hasta el final de análisis la región en estudio $(\mathrm{PH})$ no se vio afectada por sequías expresadas como valor anual.

\subsection{Sequías mensuales y rachas:}

Posteriormente fueron analizados los períodos mensuales de un mes o más con sequías que afecten al $70 \%$ de localidades o más (IMS $\geq 0.7$ ). La ubicación de las rachas mostradas en la tabla 1 muestran la ocurrencia de las principales sequías grupales (persistentes) en la Pampa Húmeda.

Una síntesis de las frecuencias absolutas y relativas de las duraciones en meses de las rachas secas se muestran en la tabla 4 .
Tabla 4 - Duración en meses de rachas secas (con IMS $\geq 0.7$ o más) ocurridas en la Pampa Húmeda. Período 1909-10/1996-97.

\begin{tabular}{ccccc}
\hline $\begin{array}{c}\text { Duración } \\
(\mathrm{mes})\end{array}$ & Casos & $\begin{array}{c}\text { Frec.Rel } \\
(\%)\end{array}$ & $\begin{array}{c}\text { Frec. Rel. } \\
\text { Acum. }(\%)\end{array}$ & Long. Rachas \\
\hline 1 & 122 & 53.04 & 100.00 & 1 mes o más \\
2 & 64 & 27.83 & 46.96 & 2 meses o más \\
3 & 21 & 9.13 & 19.13 & 3 meses o más \\
4 & 12 & 5.22 & 10.00 & 4 meses o más \\
5 & 9 & 3.91 & 4.78 & 5 meses o más \\
6 & 2 & 0.87 & 0.87 & 6 meses o más \\
\hline
\end{tabular}

Puede observarse que la mayor cantidad de rachas secas de cobertura igual o superior a 0.7 en la Pampa Húmeda han ocurrido en lapsos temporales de 1 y 2 meses, con el 53 y $80 \%$ de los casos totales. Rachas de duraciones de tres meses o más ocurren con una frecuencia del 19\% o menos.

Esta conclusión estadística muestra que la Pampa Húmeda tiene una condición climática de baja probabilidad de sequías con duración de una estación del año (tres meses o más). En términos anuales los períodos secos con IAS de $8.4 \mathrm{o}$ más ocurrieron durante los ciclos 1910-11, 1916-17, 1924-25, 1928-29, 1936-37, 1937-38, y 1944-45. También puede verse aquí que el período lluvioso reciente ha retraído al fenómeno estudiado (Minetti y otros, 1998), de tal manera que en la segunda mitad del siglo XX no se observaron períodos anuales tan secos como la condición propuesta. Inverso es el caso del centro de Chile y Comahue donde las sequías extendidas en el tiempo crecieron durante el siglo pasado.

\subsection{Síntesis temporal de las sequías anuales}

Las figuras $4 \mathrm{a}$ y $4 \mathrm{~b}$ muestran las series temporales de los índices de sequías anual con tendencia y sin tendencia respectivamente. De la figura 4a se han seleccionado como años críticos para análisis, aquellos cuyos índices de sequías superen al decil noveno $\left(\mathrm{D}_{9}\right)$ de la muestra (situaciones extremas). Ellos son: 1910-11, 1915-16, 1916-17, 1924-25, 1928-29, 1936-37, $1937-38,1944-45,1954-55$ y $1964-65$. Una vez filtrado el efecto del crecimiento de las precipitaciones ocurridas en las últimas décadas, en la serie de índices con un polinomio de tercer grado, aparecen nuevas fechas con sequías importantes a tener en cuenta. Estas sequías se presentaron en 1975-76 y 1988-89, según se ven en la figura 4b. En la mayor parte de las sequías analizadas las perdidas de precipitación oscilaron entre 300 y $600 \mathrm{~mm}$ en un año, para regiones pluviométricas de 600 a $1200 \mathrm{~mm}$ anuales en promedio, lo que representan pérdidas de $-30 \%$ a $-60 \%$ de lo normal. 
a)

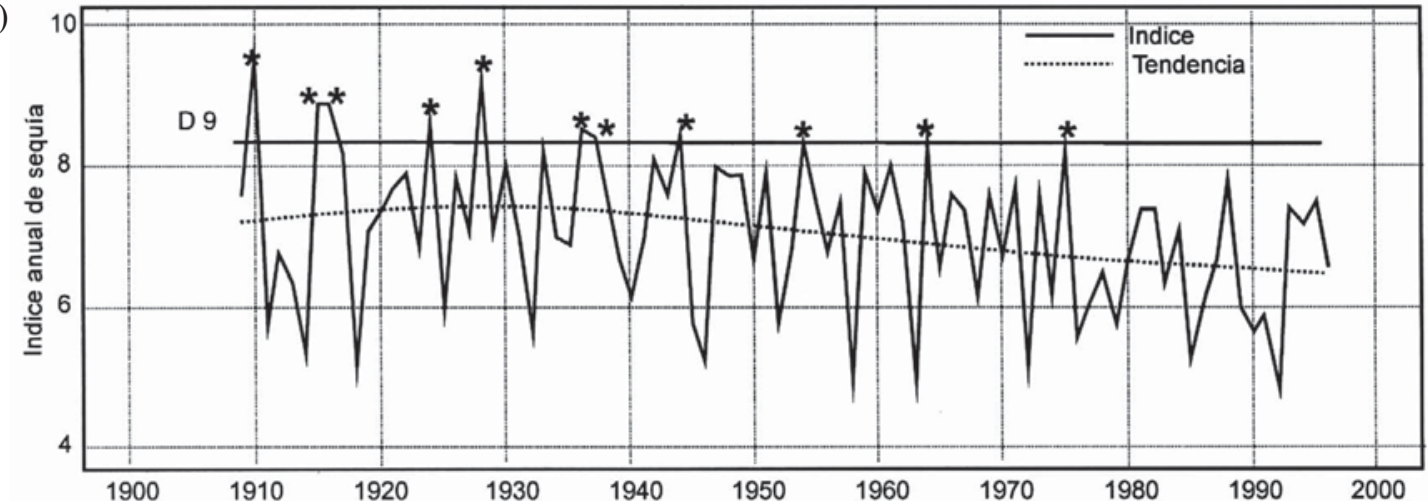

b)

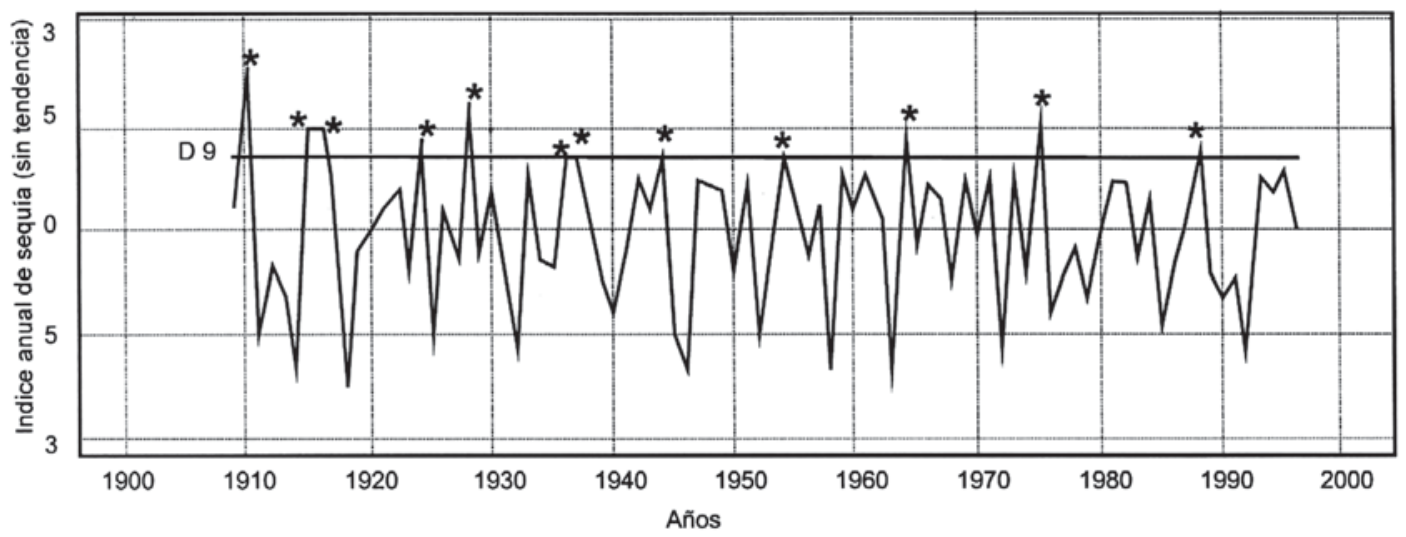

Figura 4 - (a) Indice de sequía anual con su tendencia-polinomio de 3er. grado- y decil noveno. Los puntos negros indican las campañas agrícolas donde los índices sequías superan al decil noveno. (b) Ídem anterior sin tendencia. Los valores están expresados como anomalías del índice respecto de la tendencia.

En la búsqueda de oscilaciones cuasi-periódicas de la variabilidad interanual se estimo la estructura espectral y de autocorrelaciones (figura 5) del índice de sequía anual (Tukey, 1950). Estas estimaciones fueron realizadas sobre el índice de sequía anual sin tendencia (filtrado por un polinomio de tercer orden ya que esta explicaba un alto porcentaje de la varianza). Al filtrar la tendencia, resaltan las oscilaciones de 5.6 - 6.7 años. Su correlograma muestra que una oscilación de alrededor de 7 años domina a las fluctuaciones con una inversión del signo de las anomalías de alrededor de 3 años.

Es importante destacar que esta oscilación del índice de sequía anual se encuentra dentro del rango de las variabilidades generadas por los eventos ENSO (Quinn y otros, 1978; Ropelewski y Halpert, 1987, 89; Kiladis y Diaz, 1989), analizadas con detalles en su impacto en las precipitaciones para la Pampa Húmeda por Aceituno (1988), Grimm y otros (1998), Vargas y otros (1999), entre otros. En este caso los eventos La Niña han estado asociados a sequías, mientras que su opuesto El Niño lo hicieron con excesos de precipitación. También los cambios de largo período o interdecadales observados en este índice como tendencia negativa (de sequías o positivas de precipitación) podría deberse a cambios de esta condición del mar en el Océano Pacífico ecuatorial (Minetti y otros, 2001b), aunque este aspecto, el genético, no será tratado aquí. Se destaca que en el período no se encontró la oscilación de 22 años buscada.
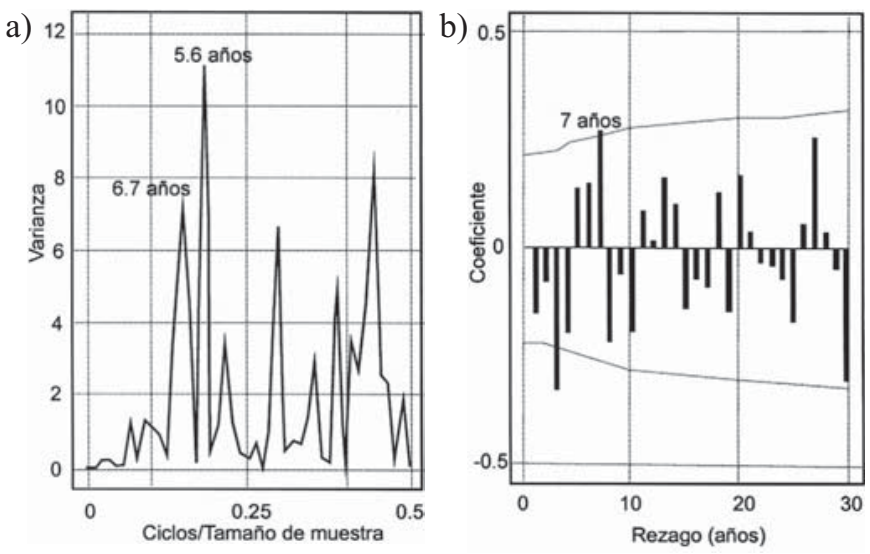

Figura 5 - (a) Correlograma del índice de sequía anual. (b) Espectro de la varianza del mismo. Se resaltan los picos espectrales significativos. 
En cuanto a la simultaneidad de ocurrencia de sequías entre regiones la figura 6 muestra una caracterización espacialtemporal de la ocurrencia de los años secos más intensos durante el período analizado. En ella se advierte una desigual ocurrencia de los mismos. Mientras que en el Norte y Centro de la Pampa Húmeda sobresale la campaña agrícola de 191011 como la sequía más intensa, la de segundo orden (1916-17) está preferentemente dominando la zona Norte con excepción de Tres Arroyos, ubicada al Sur. La sequía de 1928-29 que también está en segundo lugar de importancia tiene registros dominantes sobre el Sudoeste y Este de la provincia de Buenos Aires. Las sequías de 1924-25, 1964-65 y 1975-76 están ubicadas dispersamente y todas ellas se ubican en el tercer lugar de importancia. La sequía de 1988-89 ocupa un débil cuarto lugar, habiendo afectado a Mar del Plata.

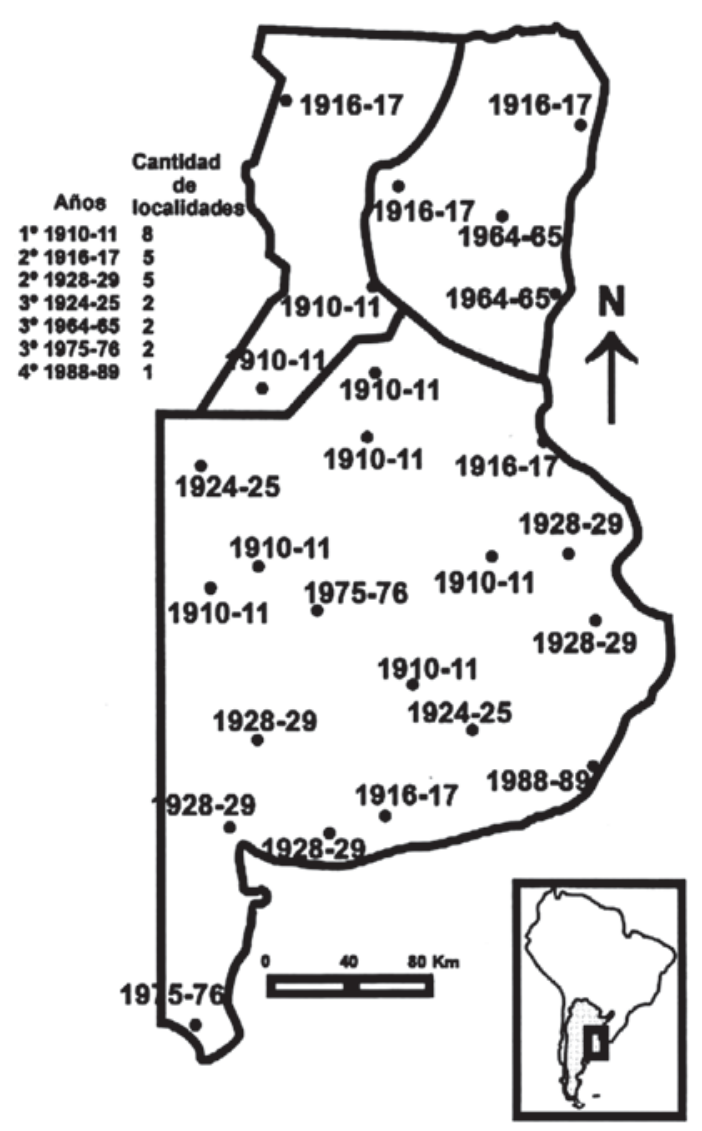

Figura 6 - Caracterización espacial-temporal de las sequías más intensas por localidades, y orden de importancia en la Pampa Húmeda.

La figura 7a muestra a las tendencias de los índices anuales de sequías de la Pampa Húmeda contrastado con las restantes regiones del cono Sur de América. Se destaca en ella la tendencia a hacia una disminución de las sequías durante el período lluvioso reciente en el llano argentino al oriente de Los
Andes y un comportamiento inverso, favorable a las sequías sobre el Centro de Chile-Comahue. Este comportamiento observado es consistente con los resultados de los modelos climáticos de simulación de producidos por el Hadley CentreInglaterra (Fonseca y otros, 2006).

La figura $7 \mathrm{~b}$ muestra el comportamiento de las tendencias de los índices de sequías por estación del año en la Pampa Húmeda. En ella se puede apreciar que en los trimestres de primavera, verano y otoño se registran tendencias decrecientes de los mismos (mayor pluviosidad) entre los que se destaca el otoño. El único trimestre que no comparte este modo, es el de invierno donde se observa una tendencia reciente de las últimas tres décadas hacia un incremento de las sequías. Esto se muestra también en la tabla anterior con las sequías estacionales críticas registradas en forma consecutiva entre los inviernos de 1993-97, asociadas en el entorno del evento La Niña 1995-96. Esta polarización del comportamiento pluvial al tornarse más lluvioso la estación cálida y seca la fría tendría que ver con un aumento de los rasgos continentales de la precipitación (monzonismo).

\subsection{Impactos de las sequías en la productividad del maíz}

Desde el punto de vista climático, es importante poder evaluar si el índice de sequía propuesto tiene asociación con los impactos en la productividad de los cereales en la $\mathrm{PH}$ y por carácter transitivo a daños económicos directos que generarían en la sociedad. Los daños de las sequías o falta de agua podrían evaluarse a través de las pérdidas directas de productividad de los cultivos regionales o experimentales mediante el uso de algún modelo empírico de diagnóstico que las explique (Sierra y Pórfido, 1980; Minetti y otros, 1982; Minetti y Lamelas, 1995). Otras pérdidas como las producidas por persistentes sequías y erosión eólica en la productividad del suelo, corrientes migratorias, lucro cesante por el no uso de un parque de maquinaria agrícola en años donde no se pudo sembrar, imposibilidad de usar ciertas tecnologías de avanzada, impedimento de cumplir con obligaciones de exportación, etc., ocasionan pérdidas más difíciles de evaluar.

Los rindes agrícolas por unidad de superficie incluidos como productividad, son los únicos datos que se disponen del cultivo en escala regional y han tenido cambios de gran escala a través del tiempo (tendencias), tal como se muestra en la figura 8a. Estos valores de productividad han pasado del orden de los $1.500 \mathrm{Kg} / \mathrm{Ha}$ a unos $4.000 \mathrm{Kg} / \mathrm{Ha}$ en el transcurso del siglo pasado. La figura $8 \mathrm{~b}$ muestra a los mismos, pero con una tendencia de tercer grado filtrando la serie. En esta última puede advertirse una oscilación interanual del orden de siete años con anomalías cambiantes de signos del orden de alrededor de tres 
a)

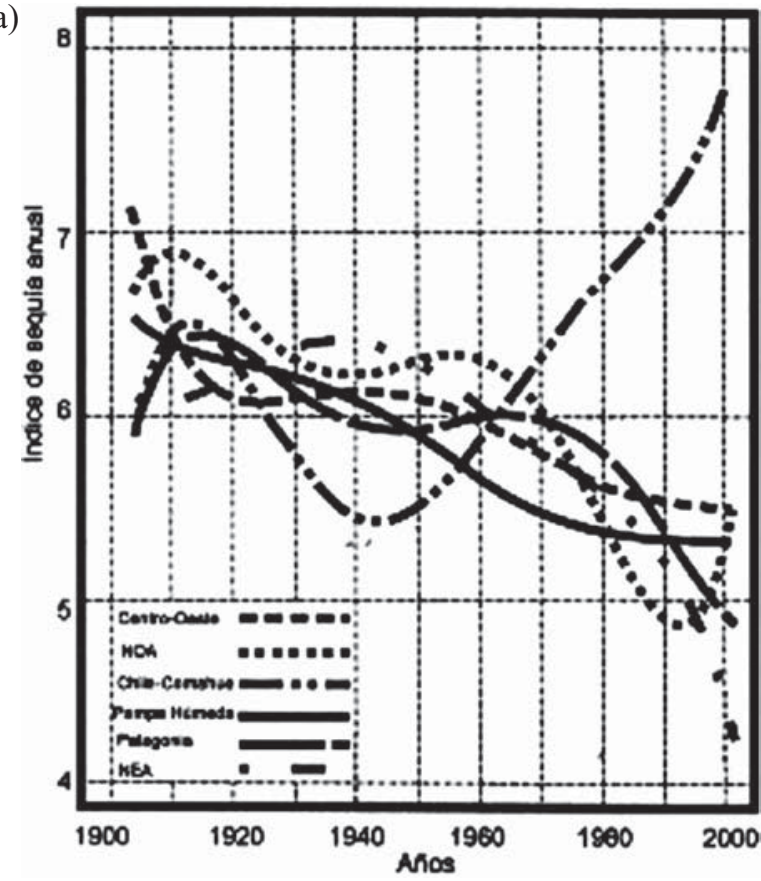

b)

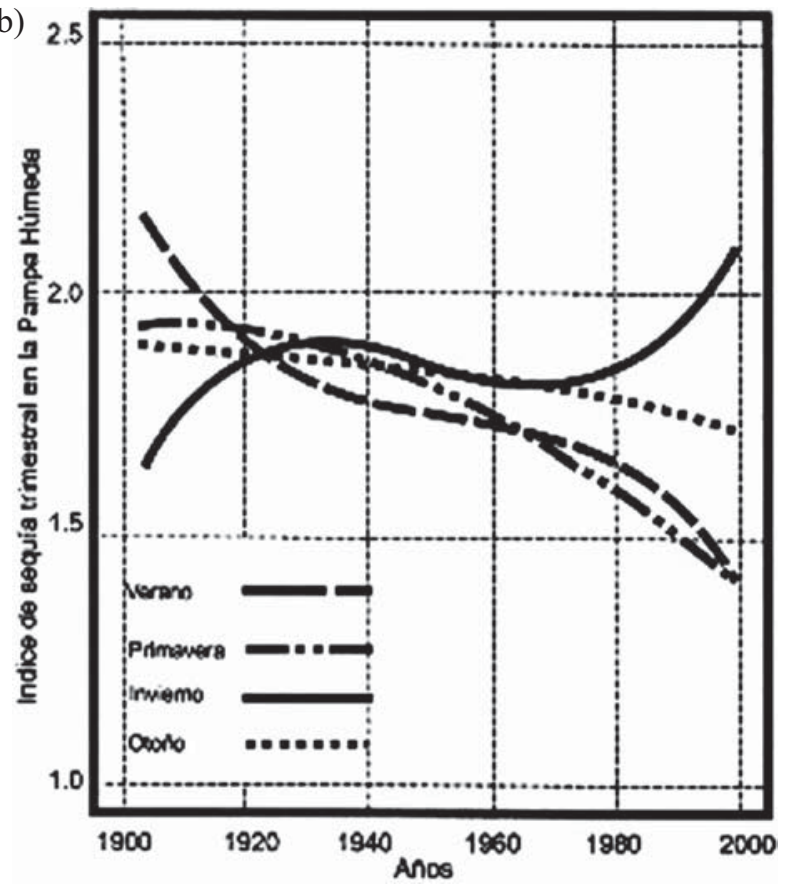

Figura 7 - (a) Tendencias de los índices de sequías anuales (IAS) regionales en el Cono Sur de América. (b) Tendencias de los índices de sequías por trimestres en la Pampa Húmeda.

años, semejante a las encontradas en el correlograma del índice de sequía anual (figura 5b), pero que no se muestra.

Las preguntas que se formulan frente a este comportamiento de los rindes, teniendo en cuenta la sensibilidad de este cultivo respecto a la falta de agua en el suelo son las siguientes:

a) En que medida la tendencia al aumento de las precipitaciones de esta región influye en la tendencia hacia un aumento de productividad mostrada en la figura $8 \mathrm{a}$.

b) Cuál es la incidencia de las oscilaciones de alta frecuencia del régimen hídrico (sequías) sobre las fluctuaciones observadas en la figura $8 b$.

Expertos en productividad de cultivos de granos de las principales praderas del mundo reconocen el efecto de la tecnología creciente en el aumento de rindes. Particularmente el uso de fertilización nitrogenada, uno de los principales nutrientes que requiere una planta del suelo ha sido mostrada como responsable del mejoramiento de los rindes en USA(Thompson, 1963, 1969, 1975). También señalan como las mejores prácticas agrícolas, la combinación de fertilización con precipitación y riego (Fogliata y Dip, 1971) que influencian positivamente en los rindes. La interacción entre estos componentes, hace que los resultados observados como tendencias no se encuentren disociados a la tendencia al aumento de las precipitaciones registradas durante la segunda mitad del siglo pasado en la Pampa Húmeda. Muchos trabajos, filtraron las tendencias de la productividad previamente, y postularon que los cambios de larga escala son únicamente debidas a la tecnología. Con los resultados filtrados recién se procedía al análisis del impacto del clima, enfermedades y otros factores (Sierra y Brinsztein, 1989, Sierra y Murphy, 1983, Seiler y otros, 1985). Estos análisis no consideraron además el probable impacto del Cambio Climático (CC) de gran escala sobre el comportamiento de especies vegetales en una región.

De estos conceptos surgiría que un procedimiento adecuado para la estimación del impacto de variables climatológicas en la productividad, seria el analizar la asociación sin filtrar las tendencias en las variables (rindes del maíz y clima) (Johnston, 1972).

Para llevar a cabo la construcción de un modelo estadístico de asociación entre variables climáticas y productividad del maíz se partió: I) del concepto anterior de relacionar los índices de sequías con la productividad sin filtrar la tendencia para incluir un análisis del impacto de ésta, y II) no considerar a las otras variables climáticas interactuantes para tener la exclusividad de análisis sobre el agua caída en la región expresada aquí como índice de sequía. Es importante destacar que aunque este índice exprese el nivel de falta de agua mediante un principio areal de cobertura y no trata la intensidad de la sequía, ya se mostró que existe una relación entre la intensidad de la sequía y su cobertura areal. 
a)

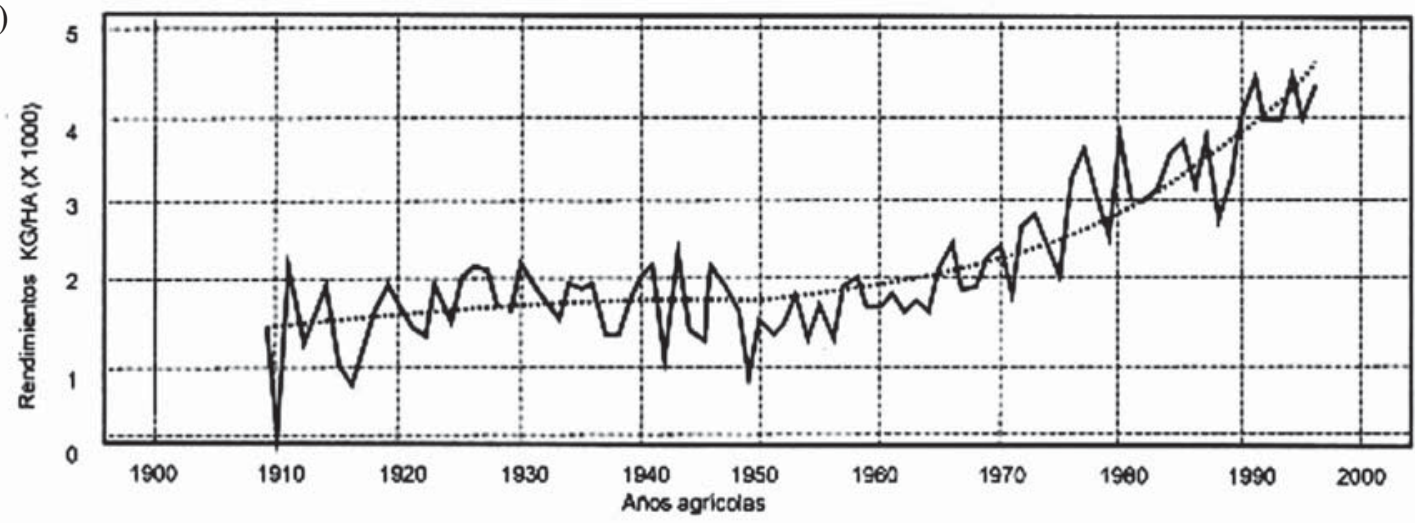

b)

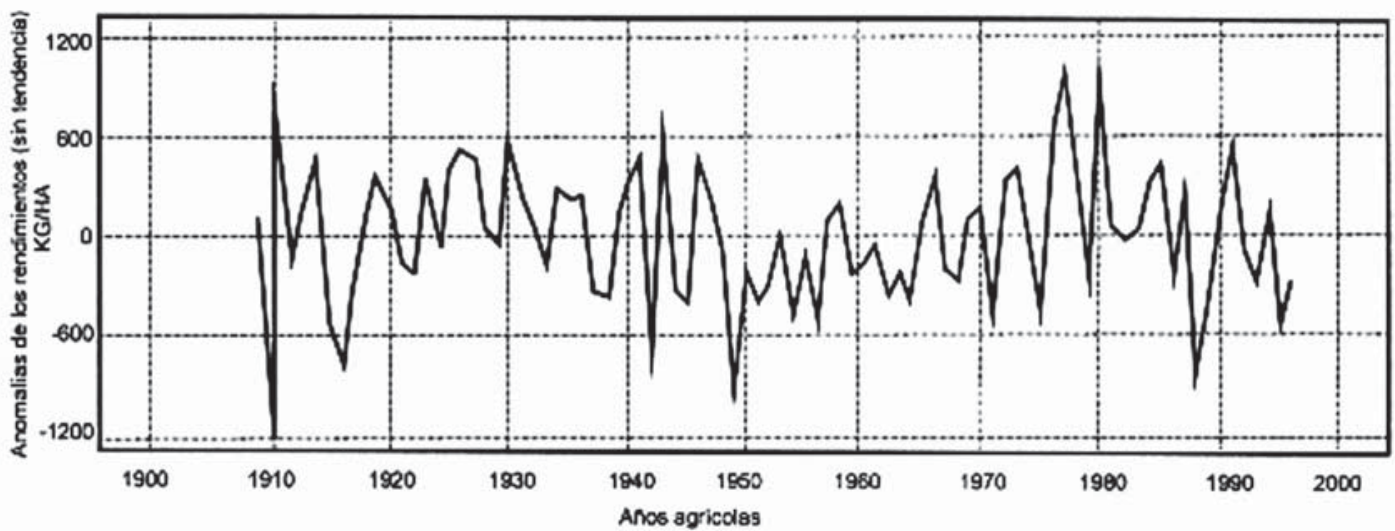

Figura 8 - (a) Rendimientos del maíz con los años y tendencia. (b) Ídem sin tendencia. Los valores se expresan como anomalías respecto de la tendencia (polinomio de $3 \mathrm{er}$. Grado).

Un análisis previo de correlación entre el índice de sequía anual con los rendimientos promedios de trigo y maíz en Argentina, indicó un mayor grado de asociación con el segundo $(\mathrm{r}$-trigo $=-0.33$ y r-maíz $=-0.43$, ambos con significación estadística del 1\%). Esto muestra la mayor sensibilidad del cultivo del maíz a las fluctuaciones hídricas, motivo por el cual se eligió este cultivo para el análisis de impacto.

Como cultivo anual, los mismos poseen diferentes fases fenológicas en su etapa de vida. El sigmoide de crecimiento que muestra una planta de crecimiento anual es equivalente a una función gausiana acumulativa (Minetti y otros 1982). En el período estacional de gran crecimiento vegetal cuando la generación de biomasa es óptima, se produce el mayor aprovechamiento de la energía disponible para la evapotranspiración (energía + agua). En este estadío la demanda de agua del cultivo es mayor, y cualquier déficit hídrico ocurrido en el mismo es de gran impacto en la productividad final.

La tabla 5 muestra las correlaciones y varianzas explicadas mensuales entre los índices de sequías y la productividad del maíz en la región. El período abarca al lapso de desarrollo del vegetal.
Tabla 5 - Correlaciones lineales y varianzas explicadas (en porcentaje) entre índices de sequía mensuales en la Pampa Húmeda y rendimientos del maíz. Período 1909-10/1996-97. Correlación crítica al 5\% rc $=0.21$ y al $1 \%$ rc $=0.28$.

\begin{tabular}{cccccc}
\hline & Oct. & Nov. & Dic. & Ene. & Feb. \\
\hline r (Correl.) & -0.31 & -0.4 & -0.33 & -0.44 & -0.04 \\
\hline $\mathbf{s}^{\mathbf{2}}$ (Expl. \%) & 9.6 & 16.9 & 11.1 & 19.9 & 0.02 \\
\hline
\end{tabular}

De esta tabla se observa que este cultivo tiene una importante sensibilidad al agua precipitada (cultivo de secano) durante el trimestre NDE. Si bien las varianzas explicadas en forma mensual son bajas, las del conjunto del período de gran crecimiento del vegetal durante el trimestre NDE aumenta considerablemente. Un modelo lineal del índice de sequía en este trimestre (NDE), explica el 33.3\% de la varianza total de los rendimientos. Una mejora de esto se consiguió solo con un modelo exponencial explicando el $37.1 \%$ de la varianza. Estos resultados se presentan en la tabla 6 . 
Tabla 6 - Correlaciones y varianzas explicadas en el trimestre NDE por diversos modelos. Período 1909-10/1996-97. La información adicional es la correspondiente a parámetros estadísticos de los modelos.

\begin{tabular}{ccc}
\hline $\begin{array}{c}\text { Trimestre } \\
\text { NDE }\end{array}$ & Modelo lineal & Modelo exponencial \\
\hline $\mathbf{r}$ (Correl.) & -0.57 & -0.60 \\
$\mathbf{s}^{\mathbf{2}}$ (Expl. \%) & 33.3 & 37.1 \\
\hline
\end{tabular}

Las figuras 9a y 9b dan cuenta de la relación entre índices de sequías del trimestre NDE con la productividad del maíz. De ellas se puede observar que:

a) No existe duda del impacto negativo que tienen los eventos secos sobre la productividad, y oscilaciones de 1200 a $4600 \mathrm{Kg} / \mathrm{Ha}$ pueden justificarse por las variaciones de las condiciones hídricas (extremos de la regresión).

b) La variabilidad de los rindes en el entorno de situaciones secas (derecha de la figura 9b) es mucho menor que las ocurridas en los eventos de elevada precipitación (izquierda). Esta conclusión no sería posible de ver en la relación lineal entre ambas variables presentadas en la figura 9a. De la misma puede inferirse que bajo situaciones de sequías, efectos tecnológicos y otros, poco pueden hacer para cambiar los rindes, y diferente es la situación con excesos de agua. Por ejemplo, en estas últimas, con suelos bien avenados (no inundables) el empleo de tecnologías específicas para cada cultivo puede hacer que se obtengan rindes muy elevados

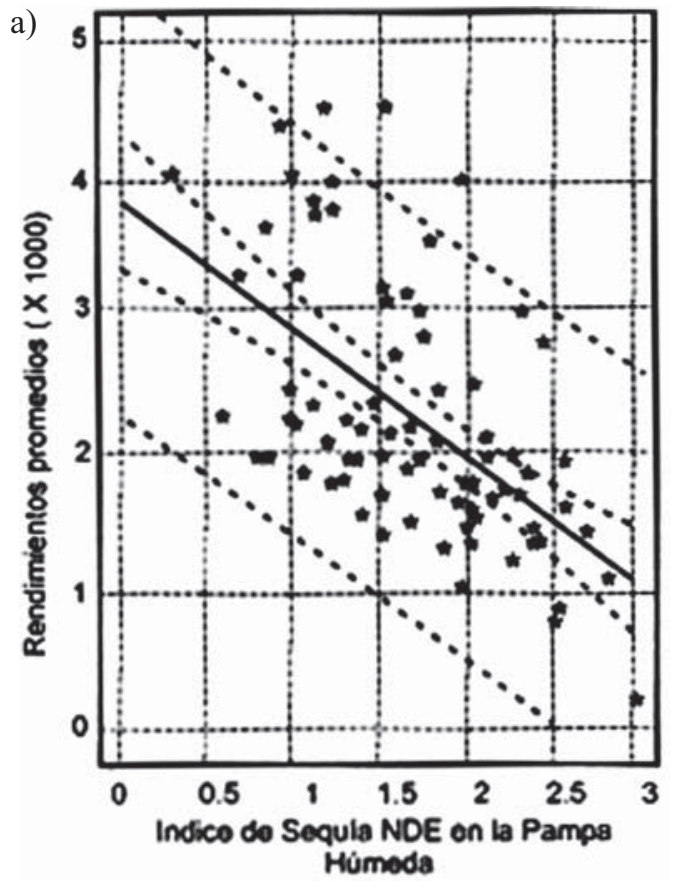

sobre los estimados en la regresión, sin embargo en suelos sobre-saturados de agua ocurren importantes pérdidas de rindes y aún la pérdida total. Esto se ve por una gran amplitud en el sector izquierdo de la figura $9 \mathrm{~b}$.

La figura 10a muestra a los valores de productividad observados y los estimados con el modelo exponencial en el período crítico de sensibilidad del cultivo al agua disponible (trimestre NDE). En ambos se han representado la tendencia para su discusión. En esta figura se ve que el salto climático ocurrido en las décadas de 1950-60 con un aumento en la precipitación total, ha impactado en los rindes agrícolas con una tendencia al crecimiento de éstos, que no serían debidos a efectos tecnológicos -un aspecto- de la discusión. Es cierto por otro lado que hay una importante tendencia no explicada directamente por el clima representada aquí entre la diferencia de ambas tendencias (tendencia observada menos la del modelo). Esto podría ser tecnología, pero aún así, efectos como la retro alimentación que existen por ejemplo entre: la biotecnología, la fertilización nitrogenada y un aumento de precipitación que coadyuvan a un aumento de los rindes (no exclusivo del nutriente), hacen que no se pueda estimar adecuadamente el impacto de este cambio en el clima sobre los rindes. Este cambio en el clima favorable a la agricultura de este cereal se ven en las figuras $4 \mathrm{a}$ y $7 \mathrm{a}$, e indican una disminución con los años de la probabilidad de ocurrencia de sequías. Aquí la última sequía importante parecería ser la de 1966-67, situación que se analizará a continuación.

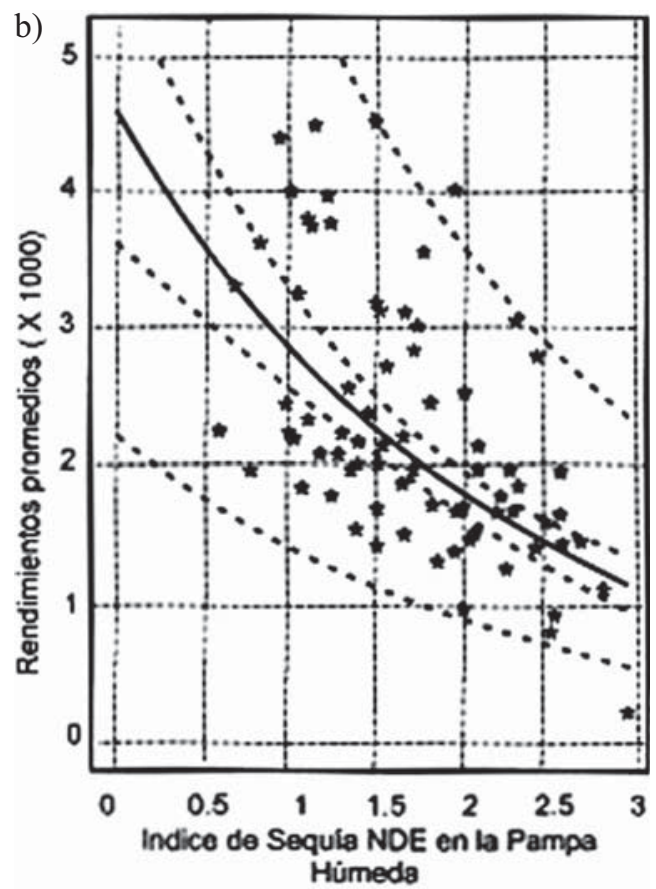

Figura 9 - (a) Regresión lineal entre el índice de sequía del trimestre NDE con la productividad del maíz. (b) Ídem con una regresión exponencial. En ambos casos se grafican los límites de confianza. 
a)

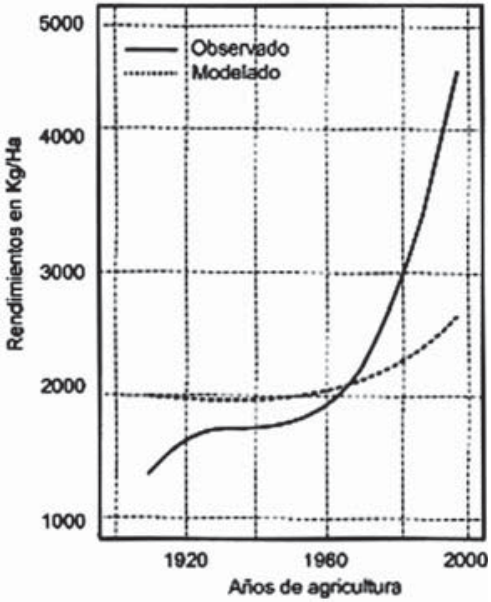

b)

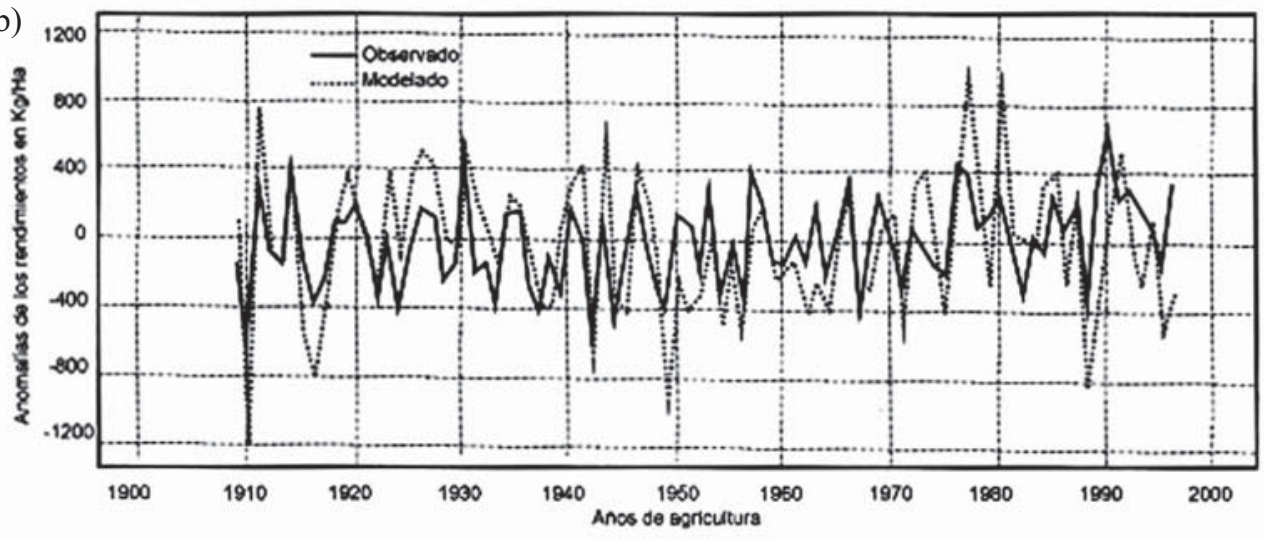

Figura 10 - (a) Tendencia de los rindes observados y modelado con la condición hídrica-sequía. El modelo no excluye la tendencia de la variable hídrica de entrada. (b) Productividad observada y pronosticada con el índice de sequía del trimestre NDE, ambas sin tendencia a los efectos de observar mejor la variabilidad interanual rápida.

Si a las series de rindes observados y modelados por efectos de las sequías se filtran por tendencia, la otra modalidad propuesta en los trabajos ya citados de Thompson, se ven los resultados de la figura 10b. En este caso una asociación entre las variables que no contemplen los cambios de largo plazo hace que la varianza explicada por la situación hídrica se acerque al 50\% (44.6\%). Si bien es cierto que esto dista de ser real ya que solo explica la variabilidad rápida y media del clima sobre el cultivo, en ella sí se ven como importantes las caídas de la productividad ocurridas durante las sequías de 1988-89 y 1995 96. También muestra lo importante que fueron ambas sequías como para hacer caer la productividad en las últimas décadas, a pesar de los aportes de las nuevas tecnologías.

\section{CONCLUSIONES}

En este trabajo se muestra que la región bajo estudio posee un régimen donde predominan las rachas secas de corta duración que la torna propicia para la agricultura de secano. Los períodos más secos anuales ocurrieron durante los ciclos agrícolas 1910-11, 1916-17, 1924-25, 1928-29, 1936-37, 1937-38, y 1944-45. El período lluvioso reciente ha retraído al fenómeno estudiado, de tal manera que en la segunda mitad del siglo pasado no se observaron períodos anuales tan secos como los registrados durante la primera mitad del Siglo XX. Una vez filtrado el efecto de larga escala (tendencia) surge que las sequías de los años 1975-76 y 1988-89 son también importantes.

Las sequías estacionales más intensas serían las del verano de 1965, otoños de 1909 y 1945, invierno de 1957 y primavera de 1910. También se identifican a los años calendarios de 1910 y 1916 como aquellos en que excepcionalmente, ocurrieron sequías en todas las estaciones climáticas del año.
En la mayor parte de los casos las pérdidas de precipitación anual en sequías severas oscilaron entre 300 y $600 \mathrm{~mm}$ en un año, para regiones pluviométricas de 600 a $1.200 \mathrm{~mm}$ anuales, y en la geografía de la región se destacan abarcando la mayor cantidad de localidades secas a las campañas de 1910-11 y 1916-17.

Del análisis temporal puede verse que la tendencia y las fluctuaciones de 5.6 - 6.7 años ocupan un importante porcentaje de la varianza y no se observan oscilaciones de 22 años. En las tendencias de largo plazo sobre las precipitaciones estacionales puede verse un sesgo de crecimiento de las precipitaciones veraniegas y lo contrario en las invernales.

Los valores de productividad del maíz, cereal utilizado para el análisis de impacto de las sequías, han pasado del orden de los $1.500 \mathrm{Kg} / \mathrm{Ha}$ a unos $4.000 \mathrm{Kg} / \mathrm{Ha}$ en el transcurso del siglo pasado. De esta tendencia parte es explicada por el crecimiento de la precipitación, otra por efectos de la tecnología y no se descarta una interacción entre ambos factores.

En la variabilidad interanual rápida el cultivo del maíz tiene una importante sensibilidad al agua precipitada en el trimestre NDE. La varianza explicada por este elemento en el período estacional, alcanza con un modelo exponencial al $37.1 \%$. Si se filtran los efectos de largo plazo antes del análisis la varianza explicada por la condición hídrica se puede llegar al $50 \%$.

Las fluctuaciones hídricas en la región pueden hacer variar a la productividad entre 1.200 a $4.600 \mathrm{Kg} / \mathrm{Ha}$. Bajo situaciones de sequías, efectos tecnológicos y otros, poco pueden hacer para cambiar los rindes, y a la inversa en situaciones de excesos de agua.

Filtrando los efectos de larga escala se ven como importantes las caídas de la productividad ocurridas durante 
las sequías de La Niña de 1988-89 y 1995-96. También esto muestra lo importante que fueron ambas sequías para hacer caer la productividad en las últimas décadas, a pesar de estar encubierta por posibles efectos tecnológicos.

\section{AGRADECIMIENTOS}

Al Laboratorio Climatológico Sudamericano-Fundación Caldenius por facilitar los datos y equipos para desarrollar el mismo., a los Servicios Meteorológicos de Argentina y Chile y Bolsa de Cereales por los datos originales. Al CONICET por el subsidio 2157 y ANPCYT por el subsidio 07-06921. A E. Mendoza por su colaboración en la elaboración de dibujos y sugerencias.

\section{BIBLIOGRAFÍA}

ACEITUNO, P., 1988: On the functioning of the Southern Oscillation in the American Sector, Part I, Surface Climate. Mon. Wea. Rev., vol. 116, 505-424.

CENTRO EDITOR DE AMÉRICA LATINA, 1984: Atlas de la actividad económica de la República Argentina, vol. 2,-El Sector Agropecuario. Atlas Total de la República Argentina.

DOORENBOS, J. YW.O. PRUITT, 1976: Las necesidades de agua de los cultivos. Estudio FAO: Riego y Drenaje 24. 194 pgs.

FOGLIATA, F.A. y R. DIP, 1971: Relación entre lluvias, producción de azúcar y fertilización nitrogenada. RIAT 48 (1), 17-28. EEAT. San Miguel de Tucumán.

HEIM, R, and J. DRACUP, 2002: A review of TwentiethCentury Drought Indices Used in the United States. America Meteorological Society . 1149-1165.August.

GRIMM, A., S. FERRAZ and J. GOMEZ., 1998: Precipitation anomalies in Southern Brazil associated with El Niño and La Niña events. J.Climate, 11, 2863-2880.

FONSECA DE CAVALCANTI, I., I. CAMILLONI y T. AMBRIZZI, 2006: Escenarios climáticos regionales. Capítulo XIII. El cambio climático en la cuenca del Plata. CONICET-IAI. 175-190. Bs.As.

HOFFMANN, J. A. J.,1988: Las variaciones climáticas ocurridas en la Argentina desde fines del siglo pasado hasta el presente. El deterioro del ambiente en la Argentina. FECIC, 275-290. Bs. As.
JOHNSTON, J., 1972: Métodos de Econometría. Edit. VicensVives. 464 pgs.

KEYANTHASH, J. and J. DRACUP, 2002: The Quantification of Drought: An Evaluation of Drought Indices. America Meteorological Society. 1167-1180. August.

KILADIS, G. N. and H. F. DÍAZ, 1989: Global climatic anomalies associated with extremes in the Southern Oscillation. J.Climate, vol. 2, 1069-1089.

KOEPPEN, W., 1931: Climatología. Fondo de Cultura Económica. México. 478 pgs.

KUGLER, W.F.,1983: Discurso Inaugural de la $7^{\text {a }}$ Reunión Nacional del CAPERAS, IDIA, Suplemento $\mathrm{N}^{\circ} 36$ INTA. Bs. As.

MARSHALL, J.R.,1972: Precipitation patterns of the United States and Sunspots.Pih D,Thesis. University of Kansas, Laurence, Kansas.

MINETTI, J.L., R.A.NEDER, J.A. MARIOTTI y C.A. GARGIULO, 1982: Respuesta de la caña de azúcar a las condiciones del clima en Tucumán. Pub.Misc. 72, 1-44. EEAOC. San Miguel de Tucumán.

MINETTI, J.L. y E.M. SIERRA,1983: Persistencia de días secos en el área cañera del Noroeste Argentino. RIAT 60(1), 97-104. San Miguel de Tucumán.

MINETTI, J.L. y C.M. LAMELAS, 1995: Respuesta regional de la soja en Tucumán a la variabilidad climática. RIAT 72 (1-2), 63-68. EEAOC. San Miguel de Tucumán.

MINETTI, J.L, and W.M. VARGAS, 1998: Trends and jumps in the annual precipitations in South America, south of the $15^{\circ} \mathrm{S}$. Atmósfera 11, 205-221. México.

MINETTI, J.L., 1999: Las sequías en la Argentina. Contribuciones Científicas de la GAEA. Sociedad Argentina de Estudios Geográficos. 60va. Semana de Geografía. 491-496. San Juan.

MINETTI, J.L., W.M. VARGAS, L.R. DE LA ZERDA, G. CASAGRANDE, L.R. ACUÑA, J.J. NIEVAS, y F.L. FRASETTO, 2001a: Inventario de las sequías regionales en Argentina y Chile. Informe Técnico del Laboratorio Climatológico Sudamericano. Fundación Caldenius. Sede NOAA y CONICET. San Miguel de Tucumán. 
MINETTI, J.L., W.M. VARGAS y A.G. POBLETE, 2001b: Observando a El Niño/La Niña con la temperatura de Lima. Rev. de Geo. Año 4, N5, 31-51. UNSJ. San Juan.

MinetTI, J.L., W.M. VARGAS, A.G. POBLETE, L.R. ACUÑA y G. CASAGRANDE, 2004: Non-linear trends and low frequency oscillations in annual precipitation over Argentina and Chile, 1931-99. Atmósfera 16, 119-135.

QUINN, W.H., D.O. ZOPP, K.S. SHORT and R.T. W.KUO YANG, 1978: Historical trends and statistics of the Southern Oscillation, El Niño, and Indonesia Droughts. Fishery Bulletin 76, 663-678.

ROBERTS, W., 1975: Relationship between solar activity and climate change. Goddard Space Flyght Center. Special Report NASA SP-366, p3. USA.

ROPELEWSKI, C. and M.S. HALPERT, 1987: Global and regional patterns associated with the El Niño/Southern Oscillation. Mon.Wea.Rev., vol. 115, 1606-1626.

ROPELEWSKI, C. and M.S. HALPERT, 1989: Precipitation Patterns Associated with the High Index Phase of the Southern Oscillation. J. Climate, col. 2, No 3, 268-284.

SEILER, R.A., R.A. FABRICIOS and V.H. ROTONDO, 1985: El impacto del clima en la variabilidad regional de los rendimientos de girasol. Proc. XI Int. Sunflower Conference, 1, 169-174. USA.

SIERRA, E.M. y O.D. PORFIDO, 1980: Factores que afectan los rendimientos en la región maicera Argentina. Rev.Fac. Agr. 1 (2), 49-64. Buenos Aires.

SIERRA, E.M. y G.M. MURPHY, 1983: Variabilidad del rendimiento en la región maicera Argentina. Meteorológica $1-2,73-86$.

SIERRA, E.M. y S.M. BRYNSZTEIN, 1989: Wheat yield variability in the SE of the province of Buenos Aires. Agr. and For.Met. 49, 1-10. USA.

STOCKTON, C.W. and D.M. MEKO, 1983: Drought recurrence in the Great Plains as reconstructed from Long-Term tree reeng records. Jou.Clim.and App.Met.. Vol. 22(1), 17-29.
THOMPSON, L.M., 1963: Weather and technology in the production of corn and soybeans. CAED Rep. 17. Iowa State University. Center of Agric. And Economic Develop.

THOMPSON, L.M., 1969: Weather and technology in the production of corn in the U.S. corn belt. Agron. J. 61, 453456. USA.

THOMPSON, L.M., 1975: Weather variability, climatic change and grain production. Science 188, 535-540. USA.

TUKEY, J.W., 1950: The sampling theory of power spectrum estimates. Symposium on Applications of Autocorrelation Analysis to Physical Problems, U.S. Office of Naval Research, NAVEXOS-P-735, pp. 47-67. Washington, D.C.

VARGAS, W.M., 1979: Atlas de excesos y déficit de humedad en la región húmeda y semiárida Argentina. Dpto. de Meteorología. UBA. 133 pgs.

VARGAS, W.M., O.C. PENALBA y J.L. MINETTi, 1999: Las precipitaciones mensuales en zonas de la Argentina y el ENOS. Un enfoque hacia problemas de decisión. Meteorológica 24 (1-2), 3-22. CAM. Buenos Aires.

VARGAS, W.M., J.L. MINETTI, and A.G. POBLETE, 2002: Low frequency oscillations in climatic and hydrological variables in southern South America's tropical-subtropical regions. The. Appl. Climatol. 72, 29-40. Springer-Verlag. Austria.

YEVJEVICH, V., 1972a: Stochastic Processes in Hidrology. Water Resources Publications fort Collins. Colorado. USA. 276 pgs.

YEVJEVICH. V., 1972b: Probability and statistics in hydrology. Publications fort Collins. Colorado. USA. 302 pgs.

WMO-World Meteorological Organization. 1966: Climate Change. Technical Note $\mathrm{n}^{\mathrm{o}}$ 79. Ginebra.

WOLCKEN, K., 1954: Algunos aspectos sinópticos de la lluvia en la Argentina. Meteoros, No 4, 327-366. SMN. Buenos Aires. 